\title{
The Case of the Missing Premise
}

\author{
DON S. LEVI University of Oregon
}

Key Words: Enthymeme approach; contrived examples; actual rhetoric; rhetorical context; PC sequence paraphrase; PC Requirement.

\begin{abstract}
This paper suggests that the flaw in the enthymeme approach to argument analysis is in the requirement, as I come to formulate it, that an argument be restated as a premises-and-conclusion sequence. The paper begins by investigating how logicians show that there are problems with the enthymeme approach. That investigation reveals a failure on the part of logicians to appreciate the importance of the rhetorical context of an argument. This failure, it is argued, is a consequence of what I refer to as the Premise-Conclusion Requirement.
\end{abstract}

When I adopt the enthymeme approach to argument analysis I run into problems. If the argument is bad as it stands, do I make it something it isn't by supplying it with missing premises that turn it into a good argument? If I am to improve it, should I consider which type of argument it is, because each type has its own standards of correctness? And how am I to strike a balance between what logical theory tells me the argument needs to be correct and what my reading seems to be disclose about what the arguer is thinking or saying? These are some of the problems I face when I try to find the missing premises of an argument.

I begin by explaining why it is wrong to conclude from a study of a contrived example anything about actual arguments. Those who think otherwise seem to suppose that a contrived sequence is a stand-in for an actual argument. I try to think of a contrived example that way, but I am not successful. Informal logicians, like Trudy Govier, are committed to basing their theorizing about the enthymeme on the study of actual rhetoric. However, when I look closely at a couple of her examples, I find that her analyses suffer because of the neglect of the rhetorical context of the examples, and I believe that the same is true of the analyses of arguments by other informal logicians. The real problem, I suggest, is with the requirement, as I come to formulate it, that an argument be restated as a premises-and-conclusion sequence, because satisfying that requirement leads to the neglect of significant rhetorical features of the argument. I try to establish this point by a consideration of an actual argument.

I know that no one shares my belief that the problem of the enthymeme is with this requirement. Like the fictional detective who refuses to work with the police but persists in questioning people who may have terrible secrets, I might only be making things worse for argument analysis because I will be walking down these mean streets of logical theory alone. 


\section{The Problem of the Enthymeme as Illustrated by Contrived Examples}

Aristotle introduced the concept of the enthymeme. He pointed out how much more effective a (syllogistic) demonstration can be when everything needed for it is not made explicit.

To show that Dorieus triumphed in a contest for which the prize is a crown, it

is enough to say "For he has been victor in the Olympic Games," without

adding "And in the Olympic Games the prize is a crown," a fact which

everybody knows (Rhetoric, 1357a16).

The speaker's ancient Greek audience would have resented being reminded of what they all knew, that the prize for winning at the Olympics was a crown of olive branches. Note how misleading it is to refer to what the speaker does not need to say as "missing" ("hidden"), since that implies that she did something wrong (van Eemeren and Grootendorst, 1983, p. 219).

But something is missing when what she said is restated in premise-conclusion form:

Dorieus has been a victor at the ancient Greek Olympics.

So, Dorieus has been a victor in a contest for which the prize is a crown.

What is missing is a statement that the prize for winning at the Olympics is a crown. No particular audience is being addressed in premise-conclusion form, and so the missing premise needs to be made explicit because nothing can be assumed about what the audience knows.

This example is supposed to be uncontroversial. Dorieus could have won something at the Olympics without having competed in an Olympic event, by winning an event not part of the regular competition. The premise is to be read as ruling out such a possibility because the example is devised to be an illustration of how sometimes information can be conveyed whose support can be given without being given completely.

Problems arise with an example that is not supposed to be uncontroversial: Benny confessed to the crime;

So, Benny is guilty.

That Benny is guilty because he confessed is by no means obvious. There seems to be a gap between premise and conclusion; the problem of the enthymeme is how this gap is to be filled.

If you apply deductive standards you look for the statements which when added as premises would make the argument valid. One way to do so is by formulating what David Hitchcock calls the argument's associated conditional, whose antecedent is the (conjunction of the) explicitly given premise(s) and whose consequent is the conclusion:

If Benny confessed then Benny is guilty.

If there really is a question about how to fill the gap from premise to conclusion then the associated conditional seems little more than a question begging assurance that it can be filled.
Why, then, suppose that the gap is to be filled at all? When there is an obvious gap, the Principle of Charity, Joel Marks says, reminds us that there is a "mental bridge" (1988, p. 308) that the arguer is relying on to close that gap; the argument or reasoning may seem bad only because some part of the thinking of the arguer has not been made explicit. "On practically any analysis," Michael Gilbert suggests (1991, p. 162), it would be formulated by generalizing the associated conditional, yielding something like:

Anyone who confesses to a crime is guilty.

The appeal of this way of formulating the missing premise is that it is mechanical, especially when the refinements introduced by David Hitchcock are included (1985, pp. 92-4). But, the generalization is so patently false. People do argue or reason badly, but no one is this foolish.

Perhaps we should apply non-deductive standards when considering what it would take to fill the gap. Inductive ones seem applicable to the present example, because we know that not all confessions are to be believed. Let us state the missing premise with this in mind:

A person who confesses to a crime is likely to be guilty.

This premise together with the premise that Benny has confessed does not guarantee that he is guilty; but, the more likely it is that he is guilty, the better the argument for Benny's guilt.

However, it is hard to imagine an arguer who could be thinking something that is to apply so generally. If a context was specified, we would have a better idea of what kinds of crimes we are discussing and where they have taken place. As a claim about a sensational crime that has gotten a lot of publicity it is obviously false because of the eagerness of certain people to confess to such crimes. And the same is true when we are talking about confessions in a police state. When no context is specified, the premise is to be understood as applying to any situation. This is what is most troubling about it; a general statement about confessions anywhere at anytime is not fairly attributable to the person giving the argument.

The real problem with the example is that it is not taken from actual discourse. Not only can't we refer to what the speaker is relying on to fill any gap in the argument because there is no speaker, but we have no way of knowing how to understand the premises or conclusion. We are not told who is saying that Benny confessed, or under what the circumstances it is being said. Perhaps the police are telling another suspect that Benny, a confederate, has confessed; perhaps Benny's confession is being announced by the authorities in a police state; or perhaps the author, speaking with authorial omniscience, by telling us that Benny confessed, means us to understand that he is guilty, in which case there would be no gap between premise and conclusion. The example is devised in order to illustrate how an argument can have a gap in it, but it seems impossible to know how to understand the statements without imagining them taken from actual discourse. 
I am emphasizing the significance of the distinction between a contrived example and one taken from actual argumentation. The Benny example is adapted from Joel Marks. Other contrived examples include: 'John is English; he is, therefore, brave' (van Eemeren and Grootendorst); 'If Mike is a dog, then Mike is an animal; therefore, Mike is not a dog' (Ennis); 'No man has feathers, so no man is a bird' (Hitchcock). What is most striking is that those who devise these artificial examples have given no thought to when someone would say such things, let alone be giving an argument.

Even Michael Gilbert's "paradigmatic enthymeme" (1991, p. 162), however realistic it seems as an argument, is not supplied with anything like a rhetorical context:

Smoking should be banned because it's bad for you.

Is it significant that the arguer talks about a ban on smoking (even in private homes?), or does he really mean to be proposing a ban on the sale of cigarettes? To know what the arguer is arguing, let alone what might be a missing premise of his argument, we would need to know why he is saying what he does, what has been said before he says why smoking should be banned, and there is no indication that Gilbert has considered such matters.'

Michael Burke, like Gilbert, neglects the rhetorical context of the examples he cites in a recent article in which he tries to show why the examples discussed in the literature are not really fallacies of denying the antecedent (Burke, 1994). The example he considers in most detail is his own "concoction": "If capital punishment deterred murder, it would be justified. Since it doesn't, it isn't." Burke's claim is that the quoted conditional is not really part of the argument; rather, it has the rhetorical function of "connecting" the arguer with his audience by indicating that his opposition is not principled, that he would endorse capital punishment if he believed that it was an deterrent. What is part of the argument is a missing premise that turned the argument into a valid instance of modus ponens: "Capital punishment is justified only if it deters." His knowledge of what is and what is not part of the argument is not based on any consideration of rhetorical context because as a "concoction" it has no rhetorical context. The same is true of the other "concoctions" he cites as illustrations. Nor does he see the need to take into account their rhetorical context even with the examples that he considers that are taken from actual philosophical discourse.

The way an argument is defined helps to explain why some logicians see nothing wrong with using concoctions as illustrations: "an argument is a collection of statements called premises and a final statement called the conclusion" (Tymoczko and Henle, 1995, p. 1). I refer to the collection of premises and conclusion as a $P C$ sequence. The definition as applied to statements, i.e., declarative sentences, devised to be elements of a PC sequence seems to be mistaken, even when each sentences is designated as 'premise' or 'conclusion', or when an argument indicator ('because'; 'so', etc.) is included. If formal (and even some informal) logicians think otherwise, it must be because of their unwarranted assumption that what is merely devised can function as does actual discourse. No one is saying anything about Benny; the sentences are devised only to be a PC sequence. The assumption that I am calling unwarranted is that these sentences can nevertheless be considered as saying something, something that can be true or false, warranted or unwarranted, acceptable or unacceptable.

The rationale for the definition is that it is based on what seems like a necessary and sufficient condition for rhetoric to be counted as an argument: it must be possible to identify something as being claimed and it must be possible to identify support that is being offered for that claim. The claim must be expressible as a declarative sentence, the conclusion, and the support as one or more declarative sentences, the premise(s). The requirement for there to be anything to logically appraise is that rhetoric be expressible as a PC sequence; what is appraised is the degree of support the premises offer for the conclusion.

It is tempting to suppose that it makes no difference whether a PC sequence is contrived or a restatement of actual rhetoric because in either case we have a claim, the conclusion, that is provided with support, the premises. But however tempting, it is wrong. The mistake is that saying that something you devise is a conclusion does not make it a real claim (statement of a position, etc.); nor does stipulating that the other sentences are to be premises make any of them real support or evidence for that claim. It may seem to those who do the devising that it is a simple matter to make an argument out of what they devise-all they have to do is imagine a rhetorical context in which the 'conclusion' really is a claim, the 'premises' really are the support. In the next section of this paper I consider just how simple a matter it really is.

My main point in this section is that it is a fallacy to conclude from a study of a contrived example anything about actual argumentation. Informal logicians will not want to quarrel with this conclusion, but even formal logicians may want to concede that only examples taken from actual rhetoric should be used to show that there are problems with the enthymeme approach.

\section{Supplying the Contrived Example with a Rhetorical Context}

Let us try to supply a context for the Benny example where it would be an argument. We are given what is supposed to be a claim, and what is supposed to be support for it. We need to imagine someone to actually make that claim and to offer as support what is given as support.

This is not easy to do. What is easy to imagine is that someone worries or believes that Benny is guilty because he is supposed to have confessed to the crime. Benny Stullwitz, who is retarded, has been arrested on a rape charge. When Benny saw the police approaching the rape scene, he ran from them. When caught, all he would say was, "I did something bad." And when lawyers from the firm where he works talk to the police they are told that he confessed. His friends can't believe that Benny could be guilty, but they are worried. Why did he run? Why did he say what he did? 
Douglas, a partner in the firm, is convinced of Benny's guilt when told what he said. He had opposed hiring Benny because Benny is retarded. That fact together with the fact that Douglas believes the worst about people explains what the "mental bridge" is between what he has been told about the case and what he believes. But the explanation does not make clear that he was doing any reasoning or giving an argument.

What might help is to imagine Douglas to get into an argument with the others.

"Benny, a rapist!" he exclaims. "I told you we never should have hired him."

"Benny couldn't do anything like that," Roxanne, a secretary with the firm, tells him angrily.

But Douglas knows better. "He did it all right. Otherwise, why did he confess? You think you know about people, but you don't-not with someone like Benny."

Is Douglas giving an argument? (Is he doing any reasoning?) "Yes," would be the logician's answer, and he would show why it is an argument by laying it out in PC sequence form:

Benny confessed; so, he is guilty.

The logician arrives at this formulation by asking himself, "What is Douglas claiming?" and "What is his support or basis for that claim?"

There are problems with this formulation. One problem is that Douglas is asking Roxanne to explain away the confession, rather than claiming that it can't be explained away. He might indicate that he is claiming it when challenged, but on the basis only of the quoted exchange with Roxanne we cannot tell he is convinced that no other explanation is possible.

Another problem is with the determination that Douglas is claiming that Benny is guilty. To see how the problem can arise, imagine Jimmy, who barely knows Benny, to be telling everyone that the retarded man who works for MacKenzie-Brackman is a rapist, after overhearing someone in the elevator say that Benny has confessed. "Are you claiming that Benny is a rapist?" someone asks Jimmy. He should resist saying that he is claiming it. After all, he is only gossiping. And I'm not sure how significant it would be if he insists that he was claiming it, especially if all he is doing is being defensive. A similar point applies to the determination of whether Douglas is actually claiming anything. Perhaps, because of his feelings about Benny's working at the firm, Douglas will insist that he is claiming that Benny is guilty of rape. But he might not be prepared to go that far without knowing more about what happened, in which case the determination that he is claiming it would be mistaken.

Still another problem is that the formulation ignores the fact that Douglas is responding to Roxanne's claim that Benny couldn't do anything like that. Douglas is saying that her knowledge of Benny counts for very little because you can't really know about people. That Roxanne doesn't know about Benny depends on the assumption that Benny is guilty, an assumption that she is unprepared to make. Douglas is drawing on her fears about Benny to insinuate that the kind of knowledge she thinks she has of Benny's character doesn't amount to much. This insinuation functions as a rhetorical ploy that takes the place of any argument he might have given for why she does not really know Benny.

When I ask myself whether Douglas has given an argument, I think of how Roxanne might respond. "It looks bad, but why don't we wait until we talk to Benny?" This response criticizes Douglas for making up his mind prematurely. But it makes no reference to any argument he is giving, and on the basis only of what Douglas has said so far there does not seem to be an argument to refer to.

So, let us imagine that Douglas to respond to Roxanne by saying, "I don't care what Benny's side of the story is. The police arrested him and say that he confessed. That's all I need to know." Here he reveals that he sides with those in power when deciding whom to believe or even to listen to. By indicating that he does not care what Benny says, he is not giving an argument for the claim that nothing that Benny says will explain away his guilt. And when we say that he takes the side of the authorities, we are not saying anything about any reasoning that provides support or a basis for his belief that Benny is guilty. In particular, we are not implying that he is relying on a sub-argument, 'The authorities say that P; so, P'. If anything, by attributing an authority bias to him we are explaining how he can arrive at his belief in Benny's guilt without having to do any reasoning.

The logician is not interested in how the question of what Douglas is claiming or what argument he is giving (or how he is reasoning) might actually arise. What I am suggesting is that the logician's perspective is not a legitimate one. The logician deceives himself when he supposes that the answer he gives about what argument Douglas is giving does not have to be understood as a response that someone in the actual situation might give. The logician deceives himself because he fails to realize the significance of the fact that he is substituting his own voice for that of someone in the situation, a point we will return to shortly.

However, even if the logician's perspective is considered legitimate, there is reason to wonder what we could learn about the problems with missing premises of other arguments from a consideration of the present example. Suppose that we credit Douglas with giving an argument when he jumps to the conclusion that Benny is guilty when he hears that Benny has confessed, an argument that is to be restated as 'Benny confessed; so Benny is guilty.' As we have noted, if he is giving an argument it does not seem to be responsive to anyone or anything. So, whatever we learn about its missing premises would not seem applicable to arguments which are responsive, especially in the face of opposition, the kinds of arguments to which the enthymeme approach is supposed to be applicable. ${ }^{2}$ We concluded the first section of this paper by pointing out that it is a fallacy to conclude anything about the enthymeme from a study of contrived or artificial arguments; a similar point is being made in this section about conclusions about 
the enthymeme based on attempts at turning a contrived example in PC sequence form into an actual argument.

The attempt in this section to make an actual argument out of a contrived example has not been successful. The lack of success is not by itself significant because it does not follow from my failure to do so that it is impossible to imagine how this contrived example could be an actual argument. What does follow is that a contrived PC sequence may not be presumed to function as a stand-in for an actual argument, and the difficulties we have had in turning the Benny example into an actual argument are being cited as evidence against that presumption. Although these difficulties do not establish that the PC model is inherently inadequate, they do encourage us to reflect on what its limitations might be.

The PC sequence seems to obscure rather than reveal the features of rhetoric that are important to take into account when trying to understand what is being argued. Consider, for example, the question of what the arguer is doing. As we saw with Jimmy or Douglas, the arguer may be just gossiping or defensively refusing to be responsive; he may be questioning or suggesting rather than making a claim or taking a position. The PC sequence seems to privilege only certain sorts of argumentative activities-demonstrating or proving, citing evidence, offering reasons in support of a position-none of which Douglas seems to be engaged in doing, despite the fact that he is saying (or believing) something which has a basis.

The PC model also may encourage us to not to be sufficiently attentive to what the speaker is doing. Consider the example that Ennis uses to illustrate his discussion of the enthymeme:

Teacher: What type of word is 'skiing' in 'skiing is dangerous'?

Student: It is a gerund because it ends in 'ing'.

The student is only trying to show that she has learned a grammatical lesson, not arguing for her classification. Treating the student's answer as having the form ' $\mathrm{C}$ (onclusion) because $\mathrm{P}$ (remise)' obscures rather than clarifies what she is doing. This point is more obvious with 'It is cold, so I should put on my coat' (Hitchcock), where we might imagine a child showing her parents that she can anticipate what they are going to tell her to do. Each example illustrate how forms such as ' $\mathrm{C}$, because $\mathrm{P}$ ' or ' $\mathrm{P}$, so $\mathrm{Q}$ ' can seem to be arguments because of the unwarranted assumption that the sequence contains what is constitutive of an argument.

The problems with the PC sequence model are not as apparent when the analyst refers to an argument without actually quoting anyone as giving it. For example, Hitchcock, when he discusses how to find missing premises, talks about the argument that marijuana should be legalized because it is no more dangerous than alcohol, or the argument that Depo-Provera is safe because it has been approved at all levels in drug testing procedures in the U.S. By not actually quoting someone as giving the argument he avoids having to confront the interpretive problems that arise when we try to understand what someone is arguing. ${ }^{3}$ The reliance on this type of example can obscure the limitations of the PC sequence model.

We have been discussing the limitations of the PC model when applied to examples that lack a rhetorical context. We turn to a discussion of its limitations when applied to actual rhetoric.

\section{Govier on the Enthymeme}

Trudy Govier's views on the enthymeme are based on what she has discovered by studying actual argumentation. Especially valuable is her attack on what she calls deductivism, which, because of its concern with determining the truth of the conclusion, approaches any argument by looking for the missing premises that make it logically correct. She complains that this approach leads to the misreading of a fallacious argument. The deductivist will respond by insisting that certain premises can be ruled out as missing because they are so implausible or because the arguer would not concede that they are premises of his argument. But, since any number of different sets of premises make an argument logically correct, it is difficult for a deductivist to decide that an argument is fallacious.

Although she cites examples from actual discourse, her discussion is hampered by the fact that she is not sufficiently concerned with the rhetorical context of the examples. ${ }^{4}$ Consider the quote from an editorial of Garrett Hardin's, "Parenthood: Right or Privilege?" (Science July 31, 1970), that she uses to illustrate how sometimes the logical gap in an argument is due to its being a bad argument, and not because it is missing a premise.

It should be easy to limit a woman's reproduction by sterilizing her at the birth of her nth child. Is this a shocking idea? If so, try this 'thought experiment': let $n=20$. Since this is not shocking, let $n$ diminish until population control is achievable.

Govier restates the argument as a PC sequence:

It would be tolerable to sterilize a woman after her twentieth child.

So, it would be tolerable to sterilize a woman at whatever point was necessary in order to achieve population control.

In this version, the argument seems to be fallacious because, as Govier, says, there is such a "morally significant" gap between the two kinds of cases (1987, p.
85 ).

She thinks that because the argument is bad, it is wrong to supply a missing premise to make the argument a good one. Each of the ones she supplies is stated in terms of what is permissible. The first is the argument's associated conditional and is merely a repetition of the argument. The other two are generalizations that are not sufficient to make the argument valid:

If it is permissible to perform an operation on a woman in an extreme case, then it is permissible to do so in a less extreme, but socially
significant case. 
If it is permissible to do anything in an extreme case, then it is permissible to do that same thing in a less extreme, but socially significant case.

Each of these makes Hardin's argument more vulnerable to attack because it commits him to much more than his original argument, and so each should be rejected as a candidate for a missing premise. Govier concludes that instead of adding a premise such as one of these, it would be better to consider the argument a fallacy.

However, there are problems with Govier's restatement of what Hardin is saying that become apparent when we compare Govier's reading of Hardin to what he is actually saying. These problems are due to her neglect of the relevant rhetorical context, and the need to reduce Hardin's rhetoric to a PC sequence is in part responsible for this neglect.

Hardin says that to sterilize a woman at the birth of her twentieth child is not a shocking idea. Govier restates this as: "It would be tolerable to sterilize a woman after her twentieth child." However, standing on its own this premise says nothing about whether the sterilization is voluntary, or about the circumstances in which the sterilization is to be performed. As it happens, Hardin is talking about forcible sterilization and advocating it on the grounds of population control: rising birth rates constitute such a serious problem that a drastic measure like forcible sterilization-arresting the mother, forcing her to go to a hospital and to be operated upon-should not be shocking, at least not to his audience of scientists. What he is saying seems to be obscured rather than illuminated by its restatement as a premise.

In his editorial Hardin is telling scientists concerned with population issues that they must be prepared to think the unthinkable-forcible sterilization of women after they have had a certain number of children. He argues that voluntary measures will probably not be sufficient because women want more babies than is good for their communities, and that forcible sterilization is preferable to jail sentences, infanticide, or compulsory abortion. He defends making women responsible by claiming that divorce and remarriage make it difficult to assign responsibility to men. To the objection that having children is a right, he responds that parents are only custodians of the community's store of germplasm.

Several issues are raised about his argument. Is the problem with forcible sterilization that it violates the right to breed? Does the right to breed imply that parents own their children? Do divorce and remarriage really make it too difficult to hold men responsible? None of these issues would arise when the focus is on Hardin's thought experiment.

Govier's restatement seems to obscure these issues because it focusses only on Hardin's thought experiment and treats it as an argument that stands alone, even though it only makes sense as a response to an anticipated objection. Given his argument that voluntary measures won't work and that sterilization is to be preferred over other coercive population control measures, and given his assumption that something must be done to control population growth, he anticipates that his audience will be reluctant to support forcible sterilization. "You wouldn't be reluctant with a woman who had twenty babies. So the question is only about how many babies you think she can have before she must be sterilized." His argument for forcible sterilization does not depend on the thought experiment, which is designed only to undermine the resistance of the opposition to what seems like a shocking suggestion.

So, the thought experiment is fallacious as she restates it, but that is because she has ignored its rhetorical context, something that the PC sequence model encourages her to do. Despite Govier's commitment to the use of actual arguments, her interest in restating the argument as a PC sequence seems to have led her to ignore significant features of the argument's context. Even if I am wrong in the reading that I am giving to Hardin's thought experiment, I want to insist that her reading is defective because it is inattentive to relevant features of the thought experiment's rhetorical context.

To show that our results are not atypical we are going to discuss an analogical argument, which Govier argues should not be treated as having a missing premise that says, in effect, that the analogy works. She insists that doing so confuses a step of the argument with meta-linguistic propositions about what it is to be an (analogical) argument. It also creates the false impression that there is some general way of evaluating analogical arguments, which she thinks are to be evaluated case-by-case, by considering what the particular analogy needs in order for it to work. As an illustration, she cites the following use of analogy by C.S. Lewis:

You can get a large audience together for a strip tease - that is, to watch a girl undress on the stage. Now suppose you came to a country where you could fill the theater simply by bringing a covered plate unto the stage, and then slowly lifting the cover so as to let everyone see, just before the lights went out, that it contained a mutton chop, or a bit of bacon, would you not think

that, in that country, something had gone wrong with the appetite for food? (Lewis, p. 75)

Govier adds, parenthetically, "Lewis is trying to defend traditional Christian morality. He uses the analogy to argue against sexual display for titillation and amusement" (1987, p. 119).

Govier's first move is to identify the premises and conclusion of Lewis's argument:

If people enjoyed watching the uncovering of a mutton chop or a bit of bacon, which they were not going to eat, then something would have gone wrong with their desire for food.

People enjoy watching a girl undress on stage when they are not going to have sexual relations with her.

So, something has gone wrong with our desire for sexual expression.

Govier believes that the correctness of this argument is a function of how close the analogy is between the hunger for food and the desire for sex. The 
argument in its restated form says nothing about why the fact that the popularity of food teases would show that something has gone wrong with the desire for food argues for there being something wrong with the enjoyment of strip teasing. What interests her is whether there is a missing premise that takes the form of a question begging reassurance that the analogy is sufficiently close.

There is something troubling about her reading if only because it seems to suggest that Lewis is bothered by the fact that the people watching the stripper are not going to have sex with her, as though his argument would not apply if we were talking about a stripper-prostitute who was going to have sex with the men watching her strip.

A reading of "Sexual Morality," the essay where Lewis uses this analogy, reveals that his theme is the virtue of chastity, which he thinks is undermined when sexual desire is detached from the desire for babies. Even a non-Christian can appreciate, he thinks, that "the biological purpose of sex is children, just as the biological purpose of eating is to repair the body." This analogy between having sex and eating leads him to compare the person who eats whenever he wants with a healthy young man who has sex whenever he has the inclination to do so. If each of his sex acts produces a baby, his "appetite is in ludicrous and preposterous excess of its function" (p. 75). This detachment of sex from procreation also explains why men enjoy watching strippers and why Lewis thinks that it is wrong-their sexual appetite is stimulated independently of any desire on their part for making a baby.

Lewis's thinking that something has gone wrong with our desire for sexual expression is based not on the analogy but on his belief that the biological function of sex implies a moral mandate not to detach the desire for sex from the desire to make babies. No doubt there are problems with the use of the analogy that might be brought out by extending it to cover an interest in the appearance, taste or smell of food that may be unrelated to an interest in nourishment, or by citing Govier as an example of how the analogy is not effective in making the very point that interests Lewis. Instead of appreciating that he is using the analogy to help us see the strip tease as a symptom of the detachment of sex from its biological function, Govier concentrates on its restatement as a PC sequence.

Govier is as good as anyone at reading arguments; if she goes wrong, a contributing factor seems to be her assumption that a restatement of rhetoric as a PC sequence is an invaluable resource when it comes to understanding what is being argued and when it comes to evaluating it. We were led to a better understanding of what Hardin and Lewis are arguing by reflecting on how the PC sequences that Govier formulates neglect important features of the arguments' rhetorical contexts. It might be thought that the $\mathrm{PC}$ restatement should be made only after it has been determined, using whatever rhetorical considerations are relevant, just what is being argued. But, I think that there will still be problems with such a restatement. Rather than explain what these problems are by a consideration of the real arguments of Hardin and Lewis-for forcible sterilization to achieve population control; for not detaching sex from
procreation-I prefer to do so by considering an example which is simpler and which raises fewer issues.

Before doing so, it is important to say more about the relationship between an argument and its restatement as a PC sequence. Whether the problems we have been experiencing are due to inadequacies inherent in the PC sequence model of an argument or to misapplications of that model should become clearer when we acquire an understanding of that relationship.

\section{The PC Requirement}

If we are very cautious we can say that restating an argument as a $\mathrm{PC}$ sequence may be of help in understanding and evaluating the argument." We run into problems when we make a stronger claim, especially one based on supposing that the PC sequence restatement is all there is to the argument." This supposition is too simple minded. The fact is that the relationship between the original argument and its PC sequence restatement is a complex one-much is lost in translation from original to $\mathrm{PC}$ sequence, even if the translation may serve certain purposes, such as focussing on the position being taken and the support being offered for that position.

What complicates the relationship is the fact that the restatement substitutes another voice for that of the original arguer, even when the analyst tries to use only the words of the arguer. How expressive the arguer is, how patronizing, respectful, engaging, moving-these and other rhetorical questions that arise concerning the original may no longer arise (or take a different form) when it comes to the restatement. So, a qualification should be introduced into the statement of the relationship between original and restatement, the qualification that the restatement is to serve certain logical purposes. Presumably, the fact that the argument is not very expressive, or that it is patronizing or even insulting, does not affect its logic.

Other rhetorical considerations are not so easily dismissed as non-logical. In the previous section we emphasized the importance of the rhetorical function that the quoted words have in the larger context of the arguer's rhetoric. Even when that function is acknowledged other considerations also are important. They include the arguer's point of view, the audience she is addressing, and the bone of contention or issue that divides her from her opposition.

These are considerations that an argument analyzer should take into account when giving a paraphrase, which, however sympathetic or faithful it is to the original, will involve some substitution of the voice of the analyst for that of the arguer. This is because the paraphrase is informed by certain questions the analyst has about what the arguer is saying. Why is the arguer taking the position she seems to be taking when a different one is more plausible or more in line with her beliefs? How is her argument limited by her point of view? How is what she is saying responsive to the opposition? These and other questions that reflect the analyst's point of view should inform the making of a paraphrase. 
There is no problem with such a paraphrase, even when given as a PC sequence, provided that the limitations imposed by the paraphraser's point of view are acknowledged. "Is the arguer taking a position on a controversial issue? If so, what is that position and how does the arguer support it?" These questions, that the PC paraphrase encourages us to ask, can be helpful in acquiring a better understanding of what argument is being given, provided that the answers are not treated as telling us everything we need to know about what is being argued for purposes of determining whether the argument is a good one.

The problem is when the PC sequence paraphrase is understood as not having a rhetorical context, and I believe that in practice this is how it is understood by most analysts, even if they never acknowledge it explicitly. The enthymeme approach contributes to this understanding because it demands that "all of the premises must be given explicitly" (Salmon, 1984, p. 7). Completeness ("all of the premises") means that everything that would not need to be said in context (because of what the arguer and audience bring to the argument) needs to be made explicit for someone who is not in the situation. The elements of the PC sequence are not to be understood as addressed to anyone or anything; nor are they to be understood as being said by any particular person or as directed at any particular opposition. I think of the absence of rhetorical context as the dirty little secret about the PC sequence paraphrase, at least when understood in terms of the enthymeme approach to argument analysis.

Whatever is lost because the PC sequence has no rhetorical context can be replaced by the inclusion of statements that are treated as missing premise of the argument. This is an obvious response by the logician who concedes that the PC sequence paraphrase has no rhetorical context. Indeed, he would want to insist that the restatement as a PC sequence satisfy what I call the PC Requirement that everything about the rhetorical context that is relevant for determining what is being argued be incorporated into its restatement as a PC sequence. The PC Requirement should not be understood to rule out the possibility of using rhetorical considerations to give a PC reading. Nor should it be understood to rule out the possibility of a critique of the (complete) PC sequence in terms of such rhetorical considerations as whether the $\mathrm{PC}$ sequence begs the question or attacks a straw man.? The PC Requirement is needed because the (complete) PC sequence is context-less. It says that everything needed in order for the sequence to actually be an argument must be built into the formulation of the elements of the $\mathrm{PC}$ sequence.

To show why the PC Requirement is problematic we consider an actual argument.

\section{The Analysis of an Actual Argument}

The example is taken from the April 19, 1980 column of Dear Abby. She had printed a letter from a woman who was distressed about her daughter's plan to give birth in the presence of her 3-year old son. Here is one of the criticisms of her reply to that letter that she printed:

Dear Abby: Surely you weren't serious when you approved allowing a 3-year old to watch his mother give birth! I am a registered nurse who has assisted in at least 5,000 births, and every time one of those supportive husbands scrubs and dons a gown to be with his wife during childbirth, I hold my breath for fear he will faint. Men in the delivery room are a pain in the neck. The bigger they are the harder they fall. Abby, please don't encourage making childbirth a family affair. We don't need fainting daddies and hysterical kids while mama is panting, puffing and pushing. Martha at St. John's

Martha is arguing against the plan to have the boy attend the delivery because of her experience with fathers at a delivery. These men intend to be supportive but they end being pains in the neck, presumably because they are uncomfortable being at the delivery. What is true of grown men is even more likely to be true of ("hysterical") young boys.

Even if concerned about the substitution of our voice for Martha's, we should not confine ourselves only to the words she actually uses when restating her argument as a PC sequence:

Martha, an RN who has assisted at more than 5,000 deliveries, holds her breath whenever a supportive husband scrubs and dons a gown to be with his wife during childbirth for fear he will faint.

Men in the delivery room are a pain in the neck.

The bigger they are the harder they fall.

We don't need hysterical kids while mama is panting, puffing and pushing.

This paraphrase seems perverse in its refusal to try to make sense of Martha's complaint, and it would not seem less perverse if we included even more of her words. This is because the approach of arranging her words as a PC sequence does her reasoning a disservice.

To help things out, it should be pointed out that although she talks as though her concern is with her own peace of mind, she is not referring to how helpful the young boy will be to health professionals like herself when she talks about what "we do not need". Her opposition to the plan is based on how she thinks other family members will do at a delivery:

Other family members do not do well when they attend a childbirth.

So, the plan to have a three year old watch his mother give birth is a bad one.

That the delivery will be a bad experience for family members such as the young boy seems a good reason for opposing the plan to have him attend.

The argument, as restated, is typical of induction. Govier is right to insist that the warrant for the induction--in this instance, that Martha's experience is an adequate basis for generalization or that the future will resemble the past - should not be included as a missing premise. She is right because it seems to say little more than that the inference is inductive. 
Given where her experience was almost certainly acquired, the induction we are attributing to her depends upon an unwarranted assumption:

The birth that the three year old is to attend will take place in a setting like the ones where Martha acquired her experience, a setting where he will not be welcome.

Martha has failed to consider the possibility that the delivery might be planned for a different kind of setting, and so it never occurs to her to wonder whether the difference in the circumstances of the delivery might constitute a significant difference.

Note that the fact that Martha is making this assumption does not mean that it is a premise of her argument. What it does mean is that she is taking it for granted without having given it any thought. It is wrong to attribute to her argument something she could not be thinking. I take it that this is the point Govier is reaching for when she criticizes some analysts for using the enthymeme approach to turn a fallacious argument into one that is logically correct.

However, there is a problem with the restatement of her argument that needs to be pointed out. The problem is that not only is the premise-'other family members do not do well at a childbirth' - not something that Martha actually says but that it reads as though it is to be understood without considering who might be saying it. What Martha says is an expression of worries that reflect her experience and point of view. Not so for the premise, which goes far beyond anything she says because it applies to any childbirth setting, regardless of whether or not family members are made to feel welcome. That it misrepresents what she says seems a consequence of the fact that what she is arguing is detached from her saying of it.

To compensate for this detachment and to be clearer about the basis for her objections, we could restate her argument to be more about explicit who Martha is:

In Martha's experience as a nurse at 5,000 deliveries, other family members do not do well at births.

So, the three year old son is likely to have a bad experience when he watches his mother give birth.

Before deciding on what might be a missing premise, there is a problem with this restatement: it refers only to the fact that she assisted as a nurse at over 5,000 births, but says nothing about where that assisting was done. All indications are that she worked in hospitals big enough for her to have attended so many deliveries, hospitals where little or nothing was done to make other family members feel welcome. If her experience was acquired elsewhere, at home deliveries or birthing centers, for example, then it would have greatly strengthened her argument for her to have cited how badly other family members do even in these settings.

The suggestion that Martha's experience was acquired in settings where family members were not made to feel welcome is based not on what she says but on what she does not say. As I pointed out, she would have argued differently if she did have experience with home deliveries or with births in facilities that encouraged other family members to attend. But, if I am right in my reading of her rhetoric, then the fact that she is talking about what is true in her experience is an essential part of what she is arguing. This argues for its inclusion in the restatement of the argument as a PC sequence. Other considerations also are important, such as that Martha is responding from the perspective of a health professional. To see why this is significant, consider that the mother is likely to respond to Martha by complaining, "You have a nerve warning me about this problem when people like you seem to be the reason for it."

If the premise is based on the assumption that the childbirth will take place in a setting where the boy's presence will be resented, then the mother will insist that this is not what she plans for him. But by changing the conclusion to fit what she does plan for him, we no longer have anything that resembles Martha's argument:

The boy is likely to have trouble watching his mother give birth if it is to take place in a setting like the ones where Martha acquired her experience.

So, it is a bad idea for the boy to watch his mother give birth in a setting where everyone makes him feel comfortable and welcome.

This restatement makes her argument absurdly bad, but that is because the conclusion reflects the mother's point of view regarding what the plans are for the delivery.

Perhaps the conclusion should reflect what Martha's reference to what "we don't need" suggests, that she really is complaining about how Abby is encouraging women at hospitals like Martha's to invite other family members to watch them give birth.

So, it is a bad idea for the boy to watch his mother give birth when the nurses in attendance do not want him there and do not try to make him feel welcome.

Not only does this have Martha attack a straw man, but it attributes to her a position on a matter she seems not to have even considered.

What we have discovered is that her conclusion is not to be understood by imagining Martha to actually say it. Otherwise it would be read as a condemnation of the plan the mother actually is making, or of a plan that the mother is not making, and neither reading is correct. So, perhaps we should include a clause that rules out wrong readings of it:

It is a bad idea for the boy to watch his mother give birth, but this is not to be understood as making any reference to the setting of the childbirth.

The clause explaining how the claim is to be understood is the handiwork of the non-participant logical analyst who is telling us how we are to understand it. Of course, it is not something that Martha could say because it presumes that there might be some significance in the setting for the childbirth, and we have been assuming that Martha has not even considered the possibility that it might 
have any significance. So, this reconstruction attributes to her an argument that she could not give, a consequence forced upon us by the PC Requirement. ${ }^{\mathrm{s}}$

An obvious reaction to the results we have been getting is to question why the features of the rhetorical context have to be incorporated into the PC sequence restatement. Granted, the results call into question whether the features can be incorporated. Rather than conclude that there is something wrong with the PC sequence model, perhaps a better conclusion would be that such rhetorical considerations, instead of being incorporated into the PC sequence, can be used to criticize the argument after it has been restated as a $\mathrm{PC}$ sequence.

One way to do this would be to criticize the argument as restated as a PC sequence for depending on the unwarranted assumption that the delivery will take place in a setting like the ones where Martha's experience was acquired. Rather than consider the assumption as a missing premise, we would be treating it, as Govier would want us to treat it, as the reason why the argument is fallacious. But, as we have already seen, this approach depends on our being able to decide on a formulation of the argument as a PC sequence, and we have not be able to make that determination, principally because of the problems we run into when we try to attribute to Martha a statement about how other family members do at a delivery.

Another way to do it would be to criticize the premise that other family members do badly at a childbirth for being much too strong a claim. As we have noted, this criticism is unfair because Martha does not make the claim. It is a claim we attributed to her when we restated her argument as a PC sequence. Because Martha does not actually make the claim, we have reason to wonder how we are supposed to understand it. It was to explain what it says that we tried to incorporate facts about the rhetorical context into the formulation of it, a strategy that backfired.

So, perhaps we should take the position that if we cannot restate Martha's rhetoric as a PC sequence, she is not giving an argument. This position saves PC analysis at the expense of the facts. Martha is objecting to the plan to have the boy watch his mother give birth. She is giving an argument against it. When I say that she is giving an argument, I am referring to what she says and does before any attempt has been made to restate her rhetoric as a PC sequence. That she is not giving an argument because what she says cannot be restated so as to satisfy the PC Requirement seems a reductio ad absurdum of the Requirement.

If logical theory has trouble putting Martha's argument into premise-conclusion form it is because of its preoccupation with the question of exactly what her argument is. This problem does not arise for informal (rhetorical) analysis because there the focus is not on laying out the argument in preparation for its assessment. "What is Martha's argument?" In informal analysis this question can be answered readily enough with a paraphrase: she is attacking the plan to have his mother watch her give birth by expressing her worries that he will become a problem at the delivery, worries that she has been led to have because of her experience with husbands who insisted on attending deliveries that she assisted.

This informal analysis exposes a number of issues raised by Martha's argument-how is her experience relevant to this particular plan? why is she more concerned with her needs than with those of the mother and her family? and requires that we think about how she would respond to these issues. But what it does not require is that we use what we discover about her thinking to revise our paraphrase of what she is arguing.

What it does require is that we anticipate how the mother would react to Martha's complaints and how Martha would respond. As I imagine it, to the mother's complaint that health professionals like Martha are responsible for the problems other family members have at a delivery, Martha would say: "I belong at the delivery," implying that the boy does not.

The mother will respond by saying that the boy belongs there too because it is her delivery and she wants him there. To this Martha will respond: "He isn't my patient; he will just be in the way." She will respond this way because she thinks of childbirth exclusively as a medical procedure. That she thinks it explains why she did not wonder whether it was going to be a home delivery, which from her point of view is not a safe setting for a medical procedure.

"What if something goes wrong?" This is how Martha is going to respond when told that childbirth is not a medical procedure. The question is a good one; childbirth is not always normal. But then no one would propose that a child be there when the delivery is likely to be complicated or remain there when it becomes complicated.

No doubt Martha will question this response, perhaps by asking whether there are reliable indices for predicting when a delivery will be a difficult one. To each criticism Martha has a response. That response in turn leads to other criticisms. This dialectic is a crucial aspect of the analysis of her argument. It is all part of an understanding of what the argument is, at least from the standpoint of an informal analysis. Of course, it would greatly facilitate the analysis to have Martha or the mother's responses; by doing all the imagining ourselves we run the risk of exercising too great a control over the course of the analysis and so using it to confirm what we already know or believe rather than to illuminate the issues. Our success as analysts depends on how successful we are in seeing things from perspectives other than our own.

But what is Martha's argument? Informal analysis answers by referring to the responses to the different questions about what Martha is arguing. But informal analysis sees no need to reformulate the argument in the light of the discoveries made by the analysis. The argument is what the analysis reveals; it is not something reconstructed on the basis of the analysis. 


\section{Conclusion}

My claim in this paper is that the real problem with the enthymeme is with the PC model of an argument. In order for there to be a problem identifying missing premises, the argument must first be restated as a sequence of sentences. If the sequence is supposed to stand completely on its own, as I have been suggesting, then the PC Requirement that certain relevant facts about the rhetorical context of the original argument be incorporated into the PC sequence restatement needs to be satisfied. I have been trying to illustrate why that can't happen without distorting or misrepresenting what is being argued. Some logicians may want to insist that the PC Requirement need not be satisfied because rhetorical facts may be cited when assessing the $\mathrm{PC}$ sequence restatement, rather than incorporated into that statement. Against this I have argued that this approach yields a PC restatement that is a misreading of the original argument.

I spent so much time on examples because I am convinced that the enthymeme approach does more harm than good when it comes to giving a reading to actual argumentation because it leads to the neglect of the rhetorical context of the argument. This neglect is not possible when contrived PC sequences are used as examples because these sequences do not have a rhetorical context, the significance of which is lost on those who rely on such examples to explain or illustrate the enthymeme. An important contributing factor to why it is lost on them is the fact that an argument when restated as a PC sequence also has no rhetorical context, especially when that sequence is taken to be the complete argument. Even logicians, like Govier, who are committed to working with examples of actual argumentation seem unaware of how the enthymeme approach leads to the identification of the argument with a contextless sequence of statements. I am not maintaining that a misreading must result from the use of the PC model; my point in this paper is that the neglect of rhetorical context which is responsible for many a misreading is promoted by the very concept of a complete PC sequence.

My position will be criticized by those of you who expect to derive from it a theory of argumentation. This criticism assumes that a theory is needed, and I want to question that assumption. My approach will also be challenged by those who will be disappointed because my discussion of the enthymeme does not even hint at the possibility of developing methods and procedures that students can utilize to find missing premises, or, for that matter, to do anything else that might be useful when analyzing arguments. Although I am sceptical about the value of methods and procedures of argument analysis, just as I am I sceptical about the need for a theory, I realize that some will believe that my approach is flawed because it seems to leave us with no lessons that can be used to teach people how to think critically.

As with other detective stories, the real mystery is not the one we set out to solve. We set out to try to find a missing premise, or, rather, what is involved in finding one. What we have stumbled on instead is more mysterious-how it is possible to satisfy the requirements for the restatement of an argument in PC form. Even more mysterious is the possibility I have just entertained, that there is no need for a theory of argumentation or lessons on critical thinking that take the form of procedures to follow when paraphrasing or analyzing an argument.

\section{Notes}

'Gilbert is encouraging us to ask questions such as "So then you'd ban alcohol as well?" As he sees it, the question really is an attack on the hidden premise "All things bad for you should be banned." He calls it enthymeme busting when we challenge the hidden principle upon which an argument depends by asking about other applications of the principle.

${ }_{2}^{2}$ This point applies even when we concede, for the sake of argument, what an anonymous referee claims: "When we hear a contrived example, such as this one, we fill in what is in essence the most common rhetorical situation in which the argument would be presented. In this case, we think of an accused criminal, not suffering from mental problems, freely confessing guilty. Thus the contrived, examples, if carefully created, can be useful for teaching argument analysis." If the most common rhetorical situation for an argument turns out to be one where there is nothing to argue about, what we learn about its missing premises seem hard to apply to arguments where there is something to argue about.

${ }^{3}$ To introduce a key illustration for his lessons on how to identify an argument's underlying assumptions, Michael Scriven asks us to suppose that we argue: "She is a homosexual and so she is probably a bad security risk." (1976, p. 167). Unlike Hitchcock, he quotes the argument. But, like Hitchcock, he says nothing about its rhetorical context.

${ }^{4}$ This neglect of context also is evident with the examples in Gough and Tinsdale (1986).

${ }^{5}$ Anthony Blair, in correspondence, understands the PC Convention: to say that "a thorough understanding and evaluation of an argument require restating it as a sequence of premises-and-conclusion." I substitute 'may be helped by' for 'require' because Blair's version has the unwelcome implication that analysts of an argument who do not restate it as the PC sequence model cannot thoroughly understand or evaluate it

${ }^{6}$ This identification of an argument with its PC restatement seems to be encouraged by such definitions as Moore and Parker's: "An argument is a set of claims, one of which, known as the principal claim or conclusion, is supposed to be supported by the rest, called the premises" (1995, p. 13). This definition seems to imply that when an argument is restated as a PC sequence, the restatement is the argument. So does Govier's definition: "An argument is a set of claims that a person puts forward in an attempt to show that some further claim is rationally acceptable. The evidence or reasons put forward ... are called the premises. The claim being defended . . . is called its conclusion" (1992, pp. 2-3). Note that the restatement is designed to be a set of claims, but surely the original claim even though it may contain some claims, also contains other kinds of rhetoric.

' In an earlier version the PC Requirement was stated as follows: "everything relevant to the understanding and evaluation of an argument be built into the restatement of it as a sequence of premises-and-conclusion." Anthony Blair pointed out that this requirement "makes it analytically true that proponents of the requirement cannot entertain rhetorical considerations in trying to understand and evaluate arguments." The requirement as stated in the present version of the paper does not rule out the possibility of using rhetorical considerations to restate or the argument as a PC sequence or to criticize the restated PC sequence because, for example, it begs the question or attacks a straw man.

${ }^{8} \mathrm{An}$ anonymous referee has two replies to these criticisms of the PC Requirement. One is that the problems with formulating the premises and conclusion are evidence only of "the ambiguity inherent in language." That there is such ambiguity seems little more than a 
sacrifice of language on the altar of logical analysis - if there are problems deciding on the formulation of the $\mathrm{PC}$ sequence, the fault is not with the $\mathrm{PC}$ requirement but with language itself! The other is that the rejection of PC reconstructions of Martha's argument presupposes that an adequate one is possible. Granted. the rejection is based on some idea of what Martha is arguing; but the referee seems to make the question begging assumption that we can know what Martha is arguing only if we can express it as a PC sequence.

* As these notes make clear, I am indebted to Anthony Blair. Trudy Govier and an anonymous referee for their comments on an earlicr version of this paper. I also am grateful io lars Hertzberg, Catherine Wilson, John Powell and John Stuhr for their comments.

\section{References}

Burke, Michael, 1985. "Unstated Premises.” Informal Logic Vol. 7, 107-18.

1994. "Denying the Antecedent: A Common Fallacy?" Informal Logic, Vol. 16, 23-30.

van Eemeren, Frans H. and Grootendorst, Rob, 1982. "Unexpressed Premises, Parts I." Journal of the American Forensics Association, Vol. 19, 97-106.

1983. "Unexpressed Premises, Parts II." Journal of the American Forensics Association, Vol. 19, 215-25.

Ennis, Robert, 1982. "Identifying Implicit Assumptions." Synthese, Vol. 63, 61-86.

Gough, James and Tinsdale, Christopher, 1985. "Hidden' or 'Missing' Premises." Informal Logic, Vol. 7, 99-106.

Gilbert, Michael, 1991. "The Enthymeme Buster: A Heuristic Procedure for Position Exploration in Dialogic Dispute." Informal Logic, Vol. 13, pp. 159-66.

Govier, Trudy, 1987. Problems in Argument Analysis and Evaluation. Dordrecht: Foris. 1989. "Analogies and Missing Premises." Informal Logic, Vol. 11, 141-52.

1992. A Practical Study of Argument. Third Edition, Belmont: Wadsworth.

1992. "What is a Good Argument?" Metaphilosophy, Vol. 23, 393-409.

Hitchcock, David, 1985. "Enthymematic Arguments." Informal Logic, Vol. 7, 83-97.

Marks, Joel, 1988. "When is a Fallacy not a Fallacy?" Metaphilosophy, Vol. 19, 307-12.

Moore, Brooke Noel and Parker, Richard, 1995. Critical Thinking, 4th Edition. Mountain View: Mayfield.

Salmon, Wesley, 1984. Logic. Englewood Cliffs: Prentice-Hall.

Scriven, Michael, 1976. Reasoning. New York: McGraw-Hill.

Tymoczko, Ron and Henle, Jim, 1995. Sweet Reason. A Field Guide to Modern Logic. New York: Freeman. 